\title{
O Sus e a Crise Atual do Setor Público da Saúde
}

Guilherme Rodrigues da Silva*

Gostaríamos de começar assinalando nossa satisfação de poder participar desta Sessão de abertura do Primeiro Encontro Paulista de Epidemiologia e agradecer aos organizadores e à Diretoria da Associação pela honrosa oportunidade.

Ao procurarmos nos desincumbir da tarefa desta fala de abertura do Encontro, pensamos inicialmente em duas alternativas de conteúdo, segundo a tendência natural de escolhas de temas entre nós. A primeira foi a de discutir alguns aspectos técnicos e metodológicos da epidemiologia aplicada ao planejamento, particularmente no que se refere ao planejamento crítico ou estratégico de políticas e ações. A segunda alternativa foi a de fazer algumas colocações que pudessem nos conduzir a refletir sobre os quadros referenciais teóricos que são necessários para a escolha e posterior interpretação de indicadores e observações empíricas, em geral, utilizáveis como fundamentação ancorada na epidemiologia, para a formulação de diretrizes das políticas públicas setoriais para determinados período e espaço sócio-geográfico. Depois de alguma hesitação, decidimos por não optar por qualquer um dos possíveis caminhos.

Tratando-se de um momento de transição em que, nas esferas do Governo Federal e do Governo do Estado, assumem o poder de Estado forças políticas nas quais muitos depositam grandes esperanças de uma atuação mais eficaz na área das políticas sociais, terminamos escolhendo tentar fazer uma síntese de numerosas manifestações e colocações recentes, que têm aparecido em periódicos da área, como na imprensa geral, sobre o que parece ser uma crise sem precedentes na organização social dos serviços de saúde e atenção médica.

Em poucos anos passamos de um momento de extremo otimismo e entusiasmo, até certo ponto justificável, para a atual sensação de perplexidade e desânimo.

* Professor Titular do Departamento de Medicina Preventiva da FM/USP 
Em 1988 conseguimos inserir na Constituição uma boa parte da proposta do Movimento Sanitário sintetizada na VIII Conferência Nacional de Saúde realizada em 1986. Foi, sem dúvida, um grande avanço a inclusão, na Constituição Federal, de uma garantia de direitos de cidadania à saúde, a mais abrangente que já se viu em uma carta magna quando comparada com a de qualquer país. A sociedade brasileira, no momento da Constituição de 1988, declarou como um de seus mais significativos preceitos éticos, o princípio do direito à equidade no acesso não apenas aos serviços como, e principalmente, aos benefícios da saúde que só podem ser alcançados quando a sociedade garante um mínimo de qualidade de vida compatível com um completo estado de bem estar físico, mental e social, historicamente possível.

Não obstante não ter sido possível viabilizar politicamente a inteiridade da proposta do movimento sanitário, devido a presença muito eficaz de reação política contrária aos avanços nesta área, logrou-se incluir na Constituição também alguns passos estratégicos fundamentais para nos aproximarmos do objetivo da equidade no acesso por parte de todos os grupos sociais. As diretrizes que mantêm o Estado como produtor direto dos serviços e ainda como principal agente de financiamento e regulamentação do setor, ao lado das normas de descentralização e municipalização tendentes a romper uma prática de décadas de excessiva centralização e verticalização na organização dos serviços, constituem uma garantia de compromisso social com a saúde.

No período após 1988, no entanto, tivemos grandes tropeços na implantação do Sistema Unico de Saúde, não obstante sua natureza desde o início restrita de "único do setor público". Neste curto espaço de tempo, como réplica do seguro privado nos Estudos Unidos da América (inclusive nos aspectos negativos mais rejeitados pela sociedade norte-americana) cresceram enormemente no Brasil os planos de pré-pagamento, ultrapassando de muito os limites das camadas médias e alguns segmentos operários ligados a setores mais dinâmicos da atividades industrial ou de serviços aos quais tem sido garantido o acesso aos serviços privados de saúde não incluídos no "Sistema Único", mediante o que contraditoriamente caracterizou-se como "universalização excludente". Como acentuaram Feveret Filho e Oliveira ${ }^{(1)}$, "o sistema como que acomoda a expulsão de grupos com tradição de participação em movimentos políticos e reivindicatórios, efetivada por mecanismos de restrições no acesso (filas grandes) e redução da qualidade" (através do "sucateamento" dos salários, instalações e equipamentos). Poderoso marketing veiculado pela mídia, apontando com insistência a "insatisfatória qualidade dos serviços públicos" e alardeando enfaticamente a eficiência da empresa privada, acompanhou passo-a-passo o desenvolvimento deste setor de serviços baseado na "universalização excludente".

Como acentuou recentemente Jairnilson Paim ${ }^{(2)}$, “... as experiências de implantação dos "Sistemas Unificados e Descentralizados de Saúde" (SUDS), 
a partir de 1987 e, mais recentemente, as tentativas de organização do "Sistema Único de Saúde", (este) com base nas leis 8.080/90 e 8.142/90, já são suficientes para revelar os sérios obstáculos criados pela administração pública brasileira contra a democratização da saúde".

Até o início da década dos 50 , o cenário da organização dos serviços de atenção médica na quase totalidade dos países era dominado por mecanismos de mercado, em que a Medicina como prática hegemônica do setor balizava a linha mestra desta organização historicamente construída pelas sociedades. $O$ Estado intervinha nas ações de controle do meio ambiente (saneamento e controle das condições de trabalho), tendo, além disto, progressivamente agregado ações de atenção médica para as populações sem acesso do mercado de serviços e como parte integrante de programas de controle de interesse social, como atenção materno-infantil, controle de doenças infecto-contagiosas etc.

Após a IIa Guerra Mundial, a retomada do progresso na economia, o avanço na organização política e a conquista de direitos mais abrangentes de cidadania, deram origem, em muitos países, a políticas mais amplas de bem-estar social com uma conseqüente maior participação estatal no financiamento e produção de serviços de saúde. Os serviços de saúde do denominado Estado de Bem-Estar Social, passaram a ser tomadas como modelos de organização em muitos países do terceiro mundo, como o Brasil e outros países de nível intermediário de desenvolvimento.

Em anos mais recentes, todavia, vimos intensificada a crítica à própria dinâmica de condução das políticas econômicas de inspiração Keynesianas, especialmente a de que os gastos com a implementação de políticas sociais como as de saúde, seriam excessivos e estariam produzindo crise expressa por níveis elevados de desemprego nestas sociedades. É compreensível que durante cada processo eleitoral em países como a Inglaterra e a Suécia essa discussão venha a baila. Mais difícil é compreender porque o desenvolvimento de argumentos deste tipo passa a incorporar-se ao discurso cotidiano nesta área. No entanto o Reino Unido gastava 7,8\% do Produto Interno Bruto (PIB), enquanto os Estados Unidos, com sua organização liberal da atenção médica gastava $14,5 \%$, no início da atual década.

Em um artigo recente, publicado no International Journal of Health Services, Charles Collins e Andrew Green ${ }^{(3)}$, pesquisadores do Nuffield Institute for Health, da Universidade de Lexds, Inglaterra, afirmam que "os governos nos países não desenvolvidos, encontram-se sob forte pressão para reduzir drasticamente sua oferta de serviços sociais. A confluência de deficits fiscais crescentes e a recessão econômica internacional, já desde os anos 70 e 80 , bem como a alta pressão das dívidas externas, forçaram os governos a negociar o pagamento dos débitos com os países industrializados e com o Fundo Monetário Internacional. Os termos dos acordos resultantes, geralmente eufemisticamente rotulados da "políticas de ajustes estruturais", têm usual- 
mente incluído medidas e metas de melhora dos balanços comerciais, de controle da inflação e de redução do deficit público. Redução, freqüentemente de grande porte, de despesas públicas especialmente na área das políticas sociais, tem sido proposta e em alguns casos implementada. As propostas de privatização para redução do setor público constitui uma das estratégias recomendadas e divulgadas em extensa bibliografia.

Neste artigo os autores discutem e mostram particularmente como as propostas de descentralização são muitas vezes consideradas como etapa intermediária para a privatização. $\mathrm{O}$ termo descentralização, em toda a sua ambigüidade e contradição, está inserido no título de numerosas monografias e publicações que surgem, como receitas para países asiáticos ${ }^{(4)}$, africanos ${ }^{(5)} \mathrm{e} d a$ América Latina ${ }^{(6)}$, por exemplo. Os autores reconhecem que, devido mesmo o caráter contraditório da política de descentralização, sua implementação pode resultar em grande avanço na busca de equidade ou em grande retrocesso no reforço da dominação da administração dos serviços por grupos oligarquicos locais. Furniss ${ }^{(7)}$, referindo-se ao caráter ambíguo do termo descentralização e à freqüência em que se recomenda tal política administrativa, ironicamente comenta: "A descentralização é um noção que está rapidamente tomando o lugar de Deus, Pátria e Funções maternas na crença popular".

O relatório de 1987 do Banco Mundial sobre o financiamento dos serviços de saúde em países não desenvolvidos ${ }^{(8)}$, bem com o relatório de $1983^{(9)}$, repetem o mesmo discurso neo-liberal que é igual ao que estamos lendo e ouvindo cotidianamente, através da televisão e da imprensa. Supõe-se que a transferência do ônus dos serviços para as organizações privadas ou para as públicas não-estatais, reduziria os custos, graças a suposta maior eficiência da empresa privada.

Podem ser identificados, nos cenários em que se manifesta a crise brasileira, sinais deste espectro de manifestações da crise internacional no campo das políticas públicas. Efetivamente, as reformas que puderam ser iniciadas nos países periféricos com nível de desenvolvimento semelhante ao do Brasil, particularmente no caso nacional, não puderam ser totalmente implementadas ou não lograram atingir bons resultados devido, basicamente, às contradições estruturais nestes países.

No clima natural de entusiasmo que se seguiu à Constituinte, muitos chegaram a acreditar que a Reforma Sanitária era objetivo a ser atingido em curto prazo, pois restavam por resolver apenas problemas administrativos ou técnicos e, portanto, politicamente neutros. A crise dos primeiros anos da corrente década, contribuiu para convencer, até mesmo os mais ingênuos, de que a implantação do SUS é complexo problema político e depende de um processo de luta de longo prazo. André Medici e colegas ${ }^{(10)}$, nos fornece um bom retrato da crise atual, tal como visto do ângulo privilegiado e decisivo do financiamento. Ao iniciarmos os anos 90 não havíamos logrado atingir um gasto em 
saúde na área dos serviços públicos que chegasse a 3\% do BID, quando no decorrer dos dois primeiros anos da década, teríamos uma redução de $40 \%$ destes gastos.

A crise dos anos 90 na Saúde era de fato a crise recrudescida da Previdência Social. Optamos na Constituinte em deixar a Saúde no âmbito da Previdência, para fins de financiamento. O termo Seguridade Social foi até tomado de empréstimo dos textos de língua castelhana. Também suposto estava que o conceito mais abrangente poderia mais facilmente nos conduzir à desejada equidade nas políticas sociais como um todo.

Parecia mais seguro garantir a utilização de recursos em montantes mais satisfatórios em um orçamento único, separado do orçamento fiscal, portanto não sujeito às injunções da legislação orçamentária anual. A dotação resultante de uma percentagem fixa das contribuições, garantiria um máximo das necessidades a serem satisfeitas com as complementações do orçamento fiscal e de fundos especiais que viessem a ser parcial ou totalmente vinculados. Não se considerou que as contribuições dependem da massa de salários e que em um momento de recessão e contenção a crise seria certa e, nestas ondições, o setor saúde seria naturalmente a área não-prioritária, por referência ao conjunto dos benefícios previdenciários, mais fundamentais para a sobrevivência das pessoas.

Depois da promulgação da lei orgânica (Lei 8080/90), acertou-se por meio de negociação que $15,5 \%$ das contribuições fossem transferidas para 0 Ministério da Saúde, quando a meta em todas as propostas era a de fixar-se um patamar (mínimo) de 30\%. Assim, já se começou "por baixo" - metade do percentual mínimo pretendido. A esta parcela, deveriam ser agregados recursos do orçamento fiscal e do então - FINSOCIAL. Em maio de 1993, o desreprezamento dos benefícios da previdência, cujo aumento havia sido aprovado pelo Congresso mas não efetivamente implementado, fez com que o Ministério da Previdência Social tivesse de usar praticamente a totalidade dos recursos arrecadados, deixando o Ministério de cumprir o acordo da transferência dos $15,5 \%^{(10)}$. A Previdência Social encerra o ano com um superávit de US $\$ 1,15$ bilhões. Este montante, no entanto, cobriria apenas os repasses de recursos que teriam de ser feitos à Saúde no primeiro trimestre de 1993.

Em 1994, muitas recordam-se, os orçamentos fiscal e da previdência social nem sequer foram aprovados. Foi mantida a política de não efetuar transferências de recursos para o Ministério da Saúde. Durante o ano o setor público da saúde foi financiado precariamente com recursos do recém-criado Fundo Social de Emergência. Este fundo foi criado, na realidade, para permitir um mínimo de flexibilidade na alocação de recursos. Foi utilizado, predominantemente, para manter equilíbrio das contas do Governo Federal.

No apagar das luzes de seu Governo, o Presidente Itamar Franco criou um programa emergencial para a Saúde com o objetivo explícito de reverter o qua- 
dro de calamidade em que se encontrava o setor. Ao que parece os resultados não alcançaram a meta do controle da situação de calamidade pública, pois a crise parece continuar inalterada. Apesar das disposições constitucionais e da lei orgânica que regulamentam o SUS, os procedimentos de financiamento desse setor continuam instáveis e indefinidos.

Vilaça-Mendes ${ }^{(11)}$ considera que em lugar da normatização prevista na Constituição, desenvolveu-se em poucos anos um modelo neo-liberal altamente discriminatório e socialmente ineficaz e ineficiente. Resultado basicamente do já mencionado peculiar processo de universalização excludente do acesso dos serviços ${ }^{(1)}$, o modelo neo-liberal caracteriza-se por três subsistemas: a) um sub-sistema de alta tecnologia que atende a 2 - 3\% da população e consome $30 \%$ dos gastos (US $\$ 755,00$ per capita ano); b) o sub-sistema de atenção supletiva, resultante do processo de universalização excludente, que atende hoje mais de 31 milhões de pessoas, dispende US $\$ 80,00$ per capita ano, de recursos que são captados pelos sistemas de pré-pagamento e seguro privado; c) o sub-sistema público que oferece serviços de qualidade cada vez mais baixa a mais de 110 milhões de brasileiros e que segundo documento do Banco Mundial ${ }^{(12)}$; está submetido a processo de morte lenta resultante do progressivo desfinanciamento (seus gastos per capita e por ano são estimados como de cerca de US\$44,00) e de conseqüente e deliberado sucateamente de instalações, equipamentos e recursos humanos.

Têm surgido numerosas propostas visando corrigir as distorções que ocultam a brutal redução dos recursos para a área da saúde desde $1990^{(10)}$. Piola ${ }^{(13)}$, em exposição em recente conclave destaca as propostas que surgiram no âmbito do Congresso Nacional e no contexto da discussão prévia sobre a reforma constitucional. Dentre elas, as mais completas são as emendas de autoria dos deputados Eduardo Jorge e Waldir Pires e a proposição do Conselho Nacional dos Secretários de Saúde (CONASS). Esta inclui mecanismos de financiamento precisos e seguros.

A crise do setor saúde em seu componente estrutural requer para sua solução ampla reforma tributária e financeira.

Ao que tudo indica o próximo cenário de luta pela implantação do SUS será o da discussão sobre as reformas fiscal e institucional que o Governo está tentando arrancar do Congresso. Para evitar que o encaminhamento das mudanças nas disposições que regem as políticas sociais no global e as da saúde em particular, seja moldado nas diretrizes neo-liberais explicitada nos vários documentos internacionais, é preciso uma grande mobilização dos mesmos setores sensíveis da sociedade civil que marcaram presença no período que precedeu a Constituinte. Esta mobilização é, a um tempo, mais difícil e mais necessária hoje, do que no período 1985-88. 


\section{Referências Bibliográficas}

1. FEVERET, FILHO, P.; \& OLIVEIRA, P.J.A. A universalização excludente: reflexões sobre as tendências do sistema de saúde. Planej. e Politicas Públicas, 3: 139-82, 1990.

2. PAIM, J.S. A gestão pública da saúde e o parlamentarismo. Saúde em Debate, 38-40, 1993.

3. COLLINS, C. \& GREEN, A. Decentralization and primary health care: some negative implications in developing countries. Int. J. Health Serv. 459-475, 1994.

4. MATHUS, R. Administrative descentralization in Asia In: Cheema; C.S. \& Rondinelli, D.A., ed. Decentralization and development. 1983; Beverly Hills, Sage, 1983.

5. NELLIS, J.R. Decentralization in north Africa In: Cheernah, G.S. \& RONDINELLI, D.A. ed., Decentralization and development. Beverly Hills, Sage, 1983.

6. RONDINELLI, D.A. \& HARRIS, R.L. Centralization and decentralization in Latin America In: Cheema, G.S. \& RONDINELLI, D.A.; ed., Decentralization and development. Beverly Hills, Sage, 1983.

7. FUNNISS,N. The practical significance of decentralization. J. Polit., 36:958-982, 1974.

8. WORLD BANK. Financing health services in: Developing countries: an agenda for reform. Washington, DC: The World Bank, 1987.

9. WORLD BANK. World development report, New York Oxford University Press, 1983.

10. MEDICI, A.C.; SOARES, LAURA T.; MARQUES, R.M. Saúde no contexto da seguridade $=$ dilemas de financiamento. [Apresentado no $4^{\circ}$ Congresso Brasileiro de Saúde Coletiva, Olinda, 1994. Resumo em Saúde em Debate; 94: 55-68, 1994).

11. VILAÇA MENDES, E. comunicação pessoal, 1992.

12. PAUL, 1988 citado por Vilaça Mendes (11).

13. PIOLA, S.F. Exposição em Painel. S. Paulo 1994; Anais A 1o Encontro Nacional de Economia da Saúde, Assoc. Brasil. de Economia da Saúde. 